\title{
What is the Return Rate of a Corporate Pension Scheme? Generalized Annuity Factors Simplify Calculation
}

\author{
Joerg Wilde ${ }^{1}$ \\ ${ }^{1}$ Pension Fund of Water Associations (Ruhrverband), Essen, Germany \\ Correspondence: Joerg Wilde, Ruhrverband, 45128 Essen, Kronprinzenstr, 37, Germany.
}

Received: January 28, 2020

Accepted: February 17, 2020

Online Published: February 18, 2020

doi:10.5430/afr.v9n1p76

URL: https://doi.org/10.5430/afr.v9n1p76

\begin{abstract}
Corporate pension schemes are widely spread especially in Northern Europe, North America, Japan. Often the major portion of defined contributions to the scheme is shouldered by the employer. A crucial question for an employee is, whether the return from his/her corporate pension plan - taking into account the corporate engagement and eventually governmental savings promotion - is favourable in comparison to other capital products for the time of retirement. This question is not answered by the absolute return in form of the future pension amount. Additionally, the employee must know the relative return, the Pension Rate of Return (PRR), in relation to what he/she has invested in form of employee contributions into the pension plan during his/her work life. Focussing on better pension information and also on counteraction to melting interest return, two current topics will be addressed. A very useful evaluation instrument for this task is the Generalized Annuity Factor (GAF). It is a generalization of the well-known Annuity Factor, which is restricted to constant payments only. With GAF any time dependent payments, e.g. linear or more complex nonlinear payments over time can be valued by a compressed closed-form formula in the same manner as constant payments by the classic Annuity Factor. Pension payments regarding mortality are such complex payments depending systematically on age. Because of its computational efficiency the new instrument simplifies calculations to be done also in smaller funds, firms or public services with common spreadsheet programs.
\end{abstract}

Keywords: retirement planning, general annuity factor, pension rate of return, present value, defined contribution, pension information

\section{JEL Classification: C02, G17, G22, J17, J26, J32}

\section{Introduction and Literature Review}

If we invest money in a capital asset, we usually ask for the rate of return before. The capital assets, we consider here, are lifetime annuities generated by defined contributions to a corporate pension scheme. In contrast to a private pension scheme, in a corporate pension scheme the employer provides contributions to the pension fund either completely or in a large part and often pays the costs of the pension fund as well. First a Pension Rate of Return (PRR) deserving the name, must include all factors on the return side having an impact on the future pension payments: on the positive side contributions, governmental savings promotion and asset returns of the pension fund, on the negative side administration costs of the fund. Furthermore, calculation of the PRR must take into account that pension payments are not absolutely certain, they depend on the survival probability in each year of retirement. On the investment side we have to consider only the fraction of the contributions paid by the employee.

A valid calculation of a PRR must take into account the time course of payments on the return side as well as on the investment side. Usually this is accomplished by the DCF-method, discounting, i.e. devaluating payments, the stronger the later they happen. That discounting rate, which leads to the equilibrium of the present values of the pension returns and of the employee contributions, will be the rate of return we are looking for. Referring to the well-known Internal Rate of Return (IRR) (Lyuu, 2002), it is henceforth referred as Pension Rate of Return (PRR).

As the PRR has to be calculated individually for a usually large number of insured members a closed formula-based calculation would be favourable for efficient computing. A possible solution could be the well-known Annuity Factor, which can be traced back to Edmond Halley (1761) and which is routinely used in many economical fields for valuation of payment processes. Unfortunately, its application is restricted to constant payment processes. As we will see later on dealing with pensions, we are faced with systematically non-constant payment processes to be valued. The constancy-restriction has now been overcome by generalization of the classic annuity factor towards a 
Generalized Annuity Factor (GAF), enabling a closed-form valuation of arbitrary time dependent processes of different time degrees (Wilde, 2005).

Accounting of pension provisions has become a very important field of application for the new tool. GAF provide an efficient, time exact and even maturity adjusted valuation of pension obligations for balance requirements and, furthermore, an anticipatory controlling of their cash and return effects. The functional approach by a $4^{\text {th }}$ order polynomial for pension payments and the direct calculation of their present value using GAF is shown in Wilde (2016). The methodical approach is also applicable to health insurance systems (see for example Guo, 2017).

In a more methodical paper of Wilde (2018) the broad economical application potential of GAF is shown exemplarily for the valuation of life-cycle models, loans and once more pension obligations. In this paper also easy to handle calculation schemes for the automatic calculation of GAF are provided to directly obtain important financial key figures like duration, present value and value at risk (VaR) in a closed form.

In a recently published German paper of Wilde (2019), at the instance of the amendment of the Insurance Regulation Law in the European Union (EU-Directive 2016/2341, 2016), a renewal of pension information for employees is proposed. The paper shows that making both, the projected pension and the according PRR, transparent to the employee will improve the understandability, comparability and usefulness of pension information. Again, GAF is a very helpful tool for this task as is exemplarily shown for a German pension fund (Pension Fund of Water Associations, 2018). The following article is mainly based on the paper mentioned above, although the focus will be more on methodical aspects.

The article is divided into four sections. After this first section, the second section introduces the methodical basics of the PRR, taking a thorough look at the underlying payment processes and their valuation: First in a two-stage-model with a past stage lasting from the entry age of the employee into the pension scheme until the actual age and with a future stage lasting from the actual age until the retirement age, we derive the payment function for the contributions paid by the employee. Second we develop a general pension payment function regarding mortality on the base of national mortality tables compressing the biometric information of the table in a $4^{\text {th }}$ order polynomial. Then easy valuation of these payment functions for arbitrary discount rates (i) is generally demonstrated just by substituting the time powers of the payment functions by the according GAF. Also, a possibility to estimate the projected pension if not available is derived. Finally, in this section the PRR will be determined as that special discount rate (i*) which leads to an equilibrium of the employee contribution value and of the pension value. All the methodical derivations are demonstrated by a concrete numerical example. The third section of the article illustrates the impact of relevant factors on PRR, e.g. the fund interest rate, the proportion of corporate contribution to the pension plan, possible governmental savings promotion, mortality differences between corporate and general population, and different entering ages in the pension scheme. In addition, the very recent problem to which extent higher employer contribution and/or higher governmental promotion could compensate lower fund interest returns will be addressed. In the fourth section after summarizing the most important results, the appropriate pension information, further application potentials and further directions of research on this subject are discussed.

\section{Methodical basics of the Pension Rate of Return (PRR)}

\subsection{Valuation of Contribution Payments of the Employee}

Contribution payments of the employee from entry into the pension fund until retirement stand for the investment of the employee in the capital asset "pension plan". In contrast to other capital assets the investment is distributed over time. From the entry into the corporation pension scheme at age $e$, the employee or Active Worker (suffix A) pays monthly contributions $C_{A}(t)$ into the pension fund until retirement age $r$, which may be determined by law or by rule of the pension fund or may be chosen by the employee in a defined age interval.

As the contribution payments are constant payment processes with or without a growth component due to salary increase, they can be directly valued using the classic Annuity Factor (Lyuu, 2002). Without growth, the Annuity Factor is

$$
a_{0}(e ; r ; q)=\frac{1-q^{r-e}}{q-1}
$$

and with growth, for example caused by a growth rate $s \%$ or equivalent by a growth factor $s=1+s \%$, the Annuity Factor is

$$
a_{0}\left(e ; r ; \frac{q}{s}\right)=\frac{1-\left(\frac{q}{s}\right)^{r-e}}{\frac{q}{s}-1}
$$


where $e$ is the starting time, $r$ is the finishing time of the payment process and $q$ is the discounting factor of an arbitrary discounting rate $i(q=1+i)$. As we see later on in chapter 2.3, formulae (1) and (1a) are the simplest cases of the General Annuity Factor (GAF) and therefore they are denoted as $a_{0}(\ldots)$ ) with a suffix 0 for constant payment processes of $0^{\text {th }}$ order.

To enable a specific treatment of the past and future service stages of the employee contribution payment process $C_{A}(t)$, we will use a two-stage-model. Because of different information quality the employee contribution payment process $C_{A}(t)$ is split in a past stage (age $e$ until actual age $x$ ) and a future stage (actual age $x$ until age $r$ ). The employee's contribution is usually defined by a fix percentage $c \%_{A}$ of his/her monthly salary. Let $S_{e}$ and $S_{x}$ denote the monthly salaries at the entry in the pension scheme (age $e$ ) and at the present time (age $x$ ). These salaries or the resulting contributions should be accessible from the accounts of the insured employees. In order to avoid detailed data access on the contribution history between $e$ and $x$, the salary development in the past can be approximated by using the geometric salary growth factor $s_{e x}=\left(S_{x} / S_{e}\right)^{-(x-e)}$. The geometric salary growth factor $s_{x r}$ reflects the long-term future salary development from now to retirement. The employee contribution payment function $C_{A}(t)$ of the active worker, split into two stages with different growth factors $s_{e x}$ resp. $s_{x r}$, and from that its employee contribution present value $\mathbf{P V}_{\mathbf{C A}}$ is then directly derived using the Annuity Factor formula (1a) as

$$
\begin{array}{ccc}
12 c \% \%_{A} & S_{e} S_{e x}{ }^{t-e} & ; t=e, \ldots, X \\
C_{A}(t)= & \\
12 \mathrm{c} \%_{\mathrm{A}} & \mathrm{S}_{\mathrm{x}} \mathrm{S}_{\mathrm{xr}}^{\mathrm{t}-\mathrm{x}} & ; \mathrm{t}=\mathrm{x}, \ldots, \mathrm{r} \\
P V_{C A}=12 c \%_{A} S_{e} a_{0}\left(e ; x ; \frac{q}{s_{e x}}\right)+\frac{12 c \%_{A}}{q^{x-e}} S_{x} a_{0}\left(x ; r ; \frac{q}{s_{x r}}\right)
\end{array}
$$

Formula (2) may be modified for simpler contribution models in practise: for example, if the contribution is a salary-independent amount $C$ per month $c \%_{A} S_{e}$ resp. $c \%{ }_{A} S_{x}$ are to be substituted by $C$ and if it is fix all the time the growth factors are set to $s_{e x}=1$ resp. $s_{x r}=1$.

The specific contribution payment function according to (2) is illustrated in Figure 1.



Figure 1. Contribution payments of the employee - in the past (grey bars) and in the future (black bars)

Figure 1 shows a typical situation often faced in practise: in the past working years between age $e$ and $x$ (here 35) normally a stronger salary increase is observed than in the future between age $x$ und $r\left(s_{e x}>s_{x r}\right)$. If there are realistic chances of promotion, a higher average future salary increase can be specified in the individual case.

In the following numerical example, all the necessary data for calculating the specific contribution payment function and its present value are introduced. 


\section{Numerical example: Calculating the present value of the employee contribution payments}

We consider an $\mathrm{x}=35$ years old Active worker (employee), who entered the pension scheme at the age of $\mathrm{e}=25$ years. The projected retirement age will be $\mathrm{r}=65$ years. The contribution rates of the pension scheme are determined as:

$\mathrm{c} \%_{\mathrm{A}}=2 \% \quad$ contribution rate of Active worker

$\mathrm{c} \%_{\mathrm{E}}=4 \% \quad$ contribution rate of Employer

$\mathrm{c} \%=\mathrm{c} \%_{\mathrm{E}}+\mathrm{c} \%_{\mathrm{A}}=6 \% \quad$ total contribution rate

The salary development of our employee is characterized by

$\mathrm{S}_{\mathrm{e}}=2,000 € \quad$ monthly salary at entry age $\mathrm{e}$

$\mathrm{S}_{\mathrm{x}}=3,000 € \quad$ monthly salary at actual age $\mathrm{x}$

$\mathrm{s}_{\mathrm{ex}}=(3000 / 2000)^{-(35-25)}=1.044 \quad$ yearly average salary increase between age $\mathrm{e}$ and $\mathrm{x}$

$\mathrm{s}_{\mathrm{xr}}=1.02 \quad$ yearly projected salary increase between age $\mathrm{x}$ and $\mathrm{r}$

The specific contribution payment function $\mathrm{C}_{\mathrm{A}}(\mathrm{t})$ then is

$$
C_{A}(t)=\begin{aligned}
& 12 * 2 \% * 2000 * 1.044^{t-25}=480 * 1.044^{t-25} ; t=25, \ldots, 35 \\
& 12 * 2 \% * 3000 * 1.02^{t-35}=720 * 1.02^{t-35} \quad ; t=35, \ldots, 65
\end{aligned}
$$

Using in advance the special discounting rate of $i^{*}=6.3 \%\left(q^{*}=1.063\right)$, which will be determined in chapter 2.4 as the equilibrium rate in the male case, we obtain annuity factors according to (1a)

$a_{0}\left(25 ; 35 ; \frac{1.063}{1.044}\right)=\frac{1-\left(\frac{1.063}{1.044}\right)^{35-25}}{\frac{1.063}{1.044}-1}=8.936 \quad$ and $\quad a_{0}\left(35 ; 65 ; \frac{1.063}{1.02}\right)=\frac{1-\left(\frac{1.063}{1.02}\right)^{65-35}}{\frac{1.063}{1.02}-1}=16.801$

The employee contribution present value $P V_{C A}$ in the male case is then

$\mathrm{PV}_{\mathrm{CA}}=480 * 8.936+\frac{1}{1.063^{35-25}} 720 * 16.801=\mathbf{1 0 8 4 1} €$

Using the equilibrium discounting rate of $i^{*}=6.9 \%$ in the female case the present value is

$\mathrm{PV}_{\mathrm{CA}}=9979 €$

These present values have to be compared with the present values of the biometric pension payments.

\subsection{Projection of the Future Pension}

The pension generated until the age of retirement does not result only from the employee contributions but also from the other sources shown in Figure 2. All these sources have an impact on the (projected) pension amount.

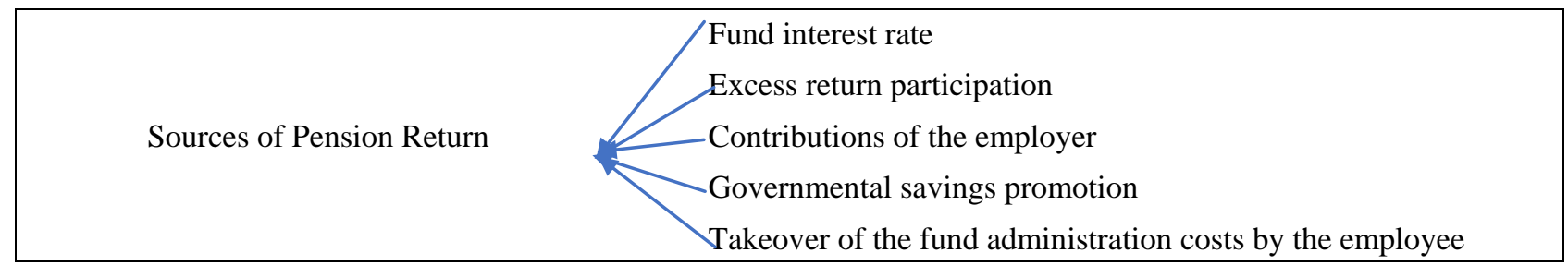

Figure 2. Sources of pension return

In many countries the insured employees have to be informed by the pension fund about their projected pension at retirement once a year (see for example EU-Directive 2016/2341, 2016). If available, this information can be used directly for modelling the pension payment process regarding mortality in chapter 2.3.

If this information is not available, it can be estimated with the data provided in the previous chapter. The projection of the pension is based on the existing covering funds $\boldsymbol{C F}_{\boldsymbol{e x}}$ generated by the past service $(e$ to $x)$ including the compounding effect of the fund interest rate $\boldsymbol{i}_{F}$ resp. factor $q_{F}$ of the pension fund

$$
C F_{e x}=12\left(c \%_{A}+c \%_{E}\right) S_{e} q_{F}^{x-e} a_{0}\left(e ; x ; \frac{q_{F}}{s_{e x}}\right)
$$

and on the expected covering funds $\boldsymbol{C F}_{x r}$ generated by the future service ( $x$ to $r$ ) which include compound interest on the already at $x$ existing covering funds $C F_{e x}$ as well

$$
C F_{x r}=12\left(c \%_{A}+c \%_{E}\right) S_{x} q_{F}^{r-x} a_{0}\left(x ; r ; \frac{q_{F}}{s_{x r}}\right)+\left(q_{F}^{r-x}-1\right) C F_{e x}
$$


The fund interest rate $i_{F}$ reflects the fund's expected returns from the capital market, it may be given as a guaranteed rate or an actuarial mandatory rate depending on the national corporate pension scheme regulations. For simplicity contribution parameters $c \%_{A}$ and $c \%_{E}$ as well as the fund interest rate $i_{F}$ are kept on a constant level in the model version described here. Of course, in practise there may be changes over the long horizon considered in corporate pension schemes. They can be modelled like the salary parameters in formula (2) differentiating for the past and the future stage.

The total covering funds accumulated until the age of retirement, the "pension pot", is the sum of (3) and (3a). Figure 3 illustrates the dynamic of the accumulation process especially in the later years, driven by the compounding effect in combination with salary increases.

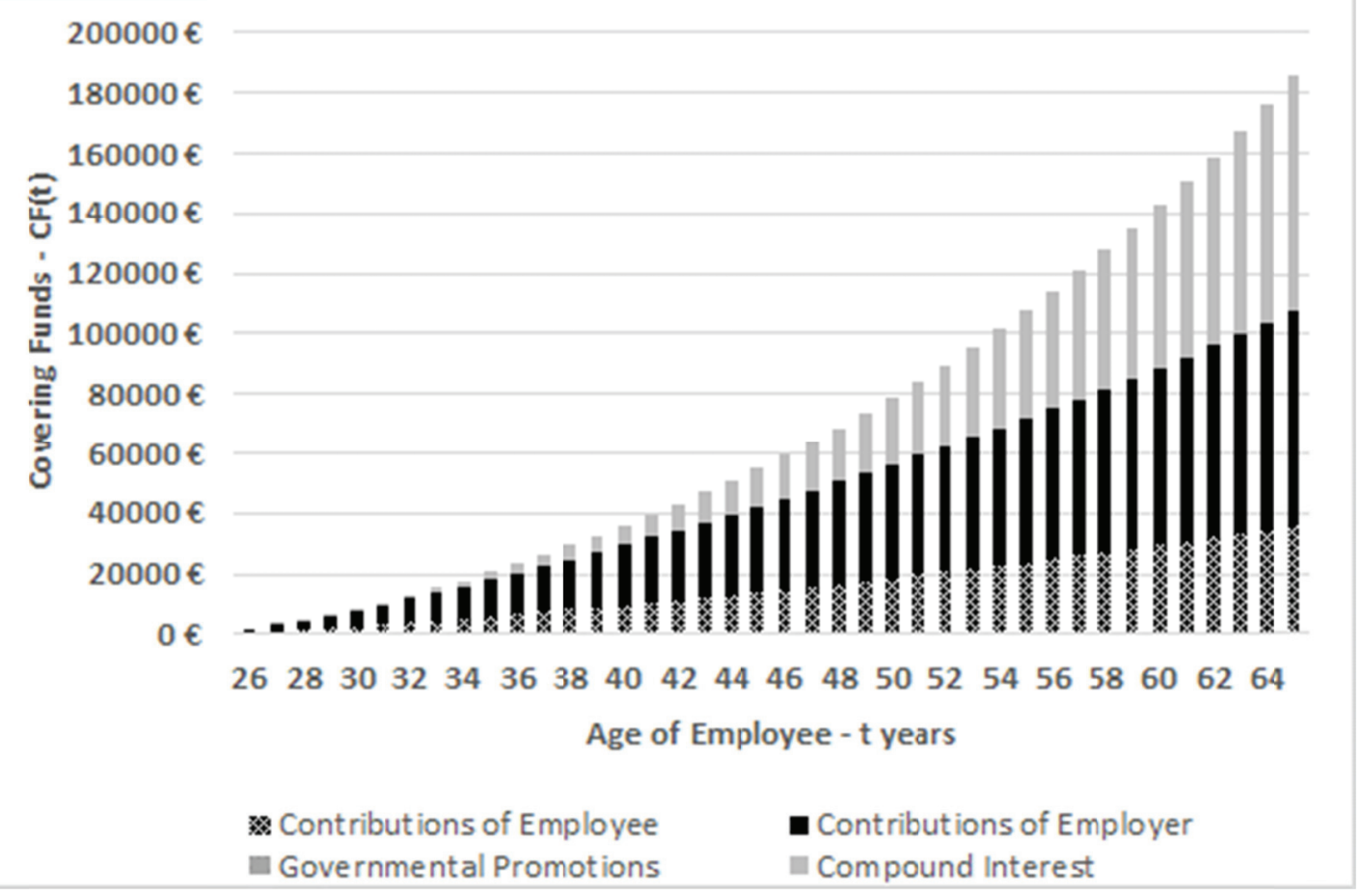

Figure 3. Development of covering funds until retirement as a result of contributions and compounded interest return (according to the numerical example)

Finally, in order to determine the absolute amount of pension $\boldsymbol{P}_{\boldsymbol{e}}$ (now on a yearly base) the sum of (3) and (3a) has to be divided by the typical present value of a unisex $1 €$-lifetime annuity $\boldsymbol{a}_{\boldsymbol{r}}^{U}$ at retirement age $\mathbf{r}$

$$
P_{e r}=C F_{e x} / a_{r}^{U}+C F_{X r} / a_{r}^{U}=P_{e x}+P_{X r}
$$

The typical $1 €$-lifetime annuity present value $a_{r}^{U}$ depends on the biometry of the insured members of the pension fund, pension indexation, bi-/unisex calculation and/or inclusion of dependants. If not available, its direct calculation using GAF in chapter 2.5 is recommended.

Splitting the projected pension into fractions originating from the pure contributions of the employee (A) and of the employer (E) and excluding interest by setting $q_{F}=1$, i.e. $i_{F}=0 \%$ we have

- for the employee

$$
\begin{aligned}
& P_{A}=12 c \%_{A}\left[S_{e} a_{0}\left(e ; x ; \frac{1}{s_{e x}}\right)+S_{x} a_{0}\left(x ; r ; \frac{1}{s_{x r}}\right)\right] / a_{r}^{U} \\
& P_{E}=12 c \%_{E}\left[S_{e} a_{0}\left(e ; x ; \frac{1}{s_{e x}}\right)+S_{x} a_{0}\left(e ; r ; \frac{1}{s_{x r}}\right)\right] / a_{r}^{U}
\end{aligned}
$$

- for the employer

$$
\text { - for the fund interest return } \quad P_{F}=P_{e r}-P_{A}-P_{E}
$$

and residually

In a causal view the fund interest return fraction of the pension has to be allocated to the employee and the employer contributions

- for the employee

$$
\begin{array}{lll}
P_{A+}=P_{A}+P_{F} & * & P_{A} /\left(P_{A}+P_{E}\right) \\
P_{E+}=P_{E}+P_{F} & * & P_{E} /\left(P_{A}+P_{E}\right)
\end{array}
$$




\section{Numerical example (continued): Calculating the projected pension at retirement and its sources}

Assuming no information about projected pension is available, the pension amount at retirement is estimated on the base of the following fund characteristics

$\mathrm{i}_{\mathrm{F}}=3.0 \%$ resp. $\mathrm{q}_{\mathrm{F}}=1.03$ fund interest rate $\mathrm{i}_{\mathrm{F}}$ resp. factor $\mathrm{q}_{\mathrm{F}}$ of the pension fund

$\mathrm{a}_{\mathrm{r}}^{\mathrm{U}}=13.29$ unisex present value of a $1 €$-lifetime annuity and a pension indexation of $\mathrm{p} \%=1 \%$

derived from the mortality table (see Chapter 2.5 )

For the pension portions generated in the past and in the future stage, using classic annuity factors

$\mathrm{a}_{0}\left(25 ; 35 ; \frac{1.03}{1.044}\right)=\frac{1-\left(\frac{1.03}{1.044}\right)^{35-25}}{\frac{1.03}{1.044}-1}=10.628 \quad$ and $\quad \mathrm{a}_{0}\left(35 ; 65 ; \frac{1.03}{1.02}\right)=\frac{1-\left(\frac{1.03}{1.02}\right)^{65-35}}{\frac{1.03}{1.02}-1}=25.882$

we find according to (3), (3a), (4) and (4a):

$\mathrm{C}_{\mathrm{ex}}=12(2 \%+4 \%) 20001.03^{35-25} 10.628=20568 €$

$\mathrm{C}_{\mathrm{xr}}=\left[12(2 \%+4 \%) 30001.03^{65-35} 25.882+20568\left(1.03^{65-35}-1\right)\right]=165052 €$

The total pension pot at retirement amounts to $185620 €$.

$\mathrm{P}_{\mathrm{ex}} \quad=20568 / 13.29=1548 €$ p.a. or $129 €$ per month

$\mathrm{P}_{\mathrm{xr}} \quad=1650502 / 13.29=12422 €$ p.a. or $1035 €$ per month

$\mathrm{P}_{\mathrm{er}} \quad=185620 / 13.29=1548+12422=13970 €$ p.a. or $1164 €$ per month

Under the conditions of our example $\left(\mathrm{c} \%=6 \%, \mathrm{i}_{\mathrm{F}}=3,0 \%\right)$ a 35year old employee can expect a monthly pension of $\mathrm{P}_{\mathrm{er}}$ $=1164 €$ at retirement age of $r=65$ years. In the first 10 years, a quarter of the work lifetime, only about $11 \%$ of the pension, $\mathrm{P}_{\mathrm{ex}}=129 €$ per month, is generated from the past service, but $\mathrm{P}_{\mathrm{xr}}=1035 €$ per month will be generated from the future service.

In respect to the sources using (5), (5a) and (5b) we obtain on a yearly base absolute (percentual) pension shares $\mathrm{P}_{\mathrm{A}}$ $=2697 €(\mathbf{1 9 . 3 \%})$ from the employee, $\mathrm{P}_{\mathrm{E}}=5394 €(\mathbf{3 8 . 6 \%})$ from the employer and $\mathrm{P}_{\mathrm{F}}=5879 €(\mathbf{4 2 . 1 \% )}$ from compound interest of the fund returns. Distributing the fund interest return on the contributions of the employee and the employer according to (6) and (6a), the result is one third to two thirds equivalent to the proportion of the contribution rates, $2 \%$ to $4 \%$.

\subsection{Valuation of Pension Payments to the Employee Regarding Mortality}

We consider pension payments to be the capital return for the capital investment of the employee contributions described in chapter 2.1. However, because of mortality, the pension payment process is a stochastic process. The realization of the pension amount calculated in chapter 2.2 in a specific year during retirement is a question of survivorship. In order to state a general formula for pension payments, not depending on unknown and arbitrary death years, we use the probabilities of survivorship derived from national mortality tables.

National probabilities of survivorship are published in mortality tables for any age up to at least 100 . The tabulated absolute probabilities of survivorship $l_{t}$ can be approximated by a unique age dependent function $l(t)$ for the relevant range of pension ages between 60 and 100. As shown in Wilde (2016), using the interpolation approach of Neville-Atkins (Phillips \& Taylor, 1996), good matches to empirical probabilities of survivorship can be achieved by an age dependent survivorship function $l(t)$, e.g. by a polynomial function such as (7) of degree $m=4$

$$
I(t)=c_{0} t^{0}+c_{1} t^{1}+c_{2} t^{2}+c_{3} t^{3}+c_{4} t^{4} \quad ; t=r, \ldots, n
$$

Looking at the male (M) and female (F) population in Germany (Statistisches Bundesamt StaBu, 2013/15) for instance, we find interpolated gender specific survivorship functions with the following coefficients $c_{k}(k=0, \ldots, 4)$

$$
\begin{gathered}
I_{M}(t)=2,372,414.420 t^{0}-130,744.643 t^{1}+2,795.686 t^{2}-26.234 t^{3}+0.099 t^{4} \\
I_{F}(t)=4,644,786.856 t^{0}-250,335.804 t^{1}+5,101.021 t^{2}-45.443 t^{3}+0.148 t^{4}
\end{gathered}
$$

These coefficients are valid as long as the mortality table is not actualised. As $l(t)$ stands for absolute survivorship probabilities of new-born persons, they have to be divided by the according survivorship probability $l_{x}$ to provide the survivorship probabilities for members having reached age $x$. 
Combining (7), in the German case for men (7a) resp. for women (7b), with the projected pension $P_{e r}$ in (4), we derive the biometric pension payment function $\boldsymbol{P}_{\boldsymbol{x}}(\boldsymbol{t})$ by $(8)$ taking also into account an expected yearly average pension increase of $\boldsymbol{p} \%(p=1+p \%)$. As GAF can be applied to a payment function in the same manner as the classic annuity factor, substituting time terms $t^{k}$ in (8) by the according GAF $a_{k}(r ; n ; q)$ as shown in (1) to (1e) below, we also obtain directly its present biometric pension value $\boldsymbol{P} \boldsymbol{V}_{\boldsymbol{P} \boldsymbol{x}}$ as

$$
\begin{aligned}
& P_{X}(t)=P_{e r} \frac{l(t)}{l_{x}} p^{t-r}=\frac{P_{e r}}{l_{x}}\left[c_{0} t^{0}+c_{1} t^{1}+c_{2} t^{2}+c_{3} t^{3}+c_{4} t^{4}\right] p^{t-r} \quad ; t=r, \ldots, n \\
& P V_{P X}=\frac{1}{q^{r-e}} \frac{P_{e r}}{l_{x}}\left[c_{0} a_{0}\left(r ; n ; \frac{q}{p}\right)+c_{1} a_{1}\left(r ; n ; \frac{q}{p}\right)+c_{2} a_{2}\left(r ; n ; \frac{q}{p}\right)+c_{3} a_{3}\left(r ; n ; \frac{q}{p}\right)+c_{4} a_{4}\left(r ; n ; \frac{q}{p}\right)\right]
\end{aligned}
$$

General Annuity Factors $\boldsymbol{a}_{\boldsymbol{k}}(\boldsymbol{r} ; \boldsymbol{n} ; \boldsymbol{q}), \mathrm{k}=0, \ldots, 4$, used in (8a), can be easily computed in a recursive manner starting from the classic Annuity Factor $\boldsymbol{a}_{\boldsymbol{0}}(\boldsymbol{r} ; \boldsymbol{n} ; \boldsymbol{q})$ subject to (1) by the following bootstrap procedure (Wilde, 2005 and 2018):

$$
\begin{gathered}
a_{0}(r ; n ; q)=\left[1-q^{r-n}\right] /(q-1) \\
a_{1}(r ; n ; q)=\left[1+(r+1)^{1}-(n+1)^{1} q^{r-n}+a_{0}(r ; n ; q)\right] /(q-1) \\
a_{2}(r ; n ; q)=\left[1+(r+1)^{2}-(n+1)^{2} q^{r-n}+a_{0}(r ; n ; q)+2 a_{1}(r ; n ; q)\right] /(q-1) \\
a_{3}(r ; n ; q)=\left[1+(r+1)^{3}-(n+1)^{3} q^{r-n}+a_{0}(r ; n ; q)+3 a_{1}(r ; n ; q)+3 a_{2}(r ; n ; q)\right] /(q-1) \\
a_{4}(r ; n ; q)=\left[1+(r+1)^{4}-(n+1)^{4} q^{r-n}+a_{0}(r ; n ; q)+4 a_{1}(r ; n ; q)+6 a_{2}(r ; n ; q)+4 a_{3}(r ; n ; q)\right] /(q-1)
\end{gathered}
$$

If a yearly indexation $\boldsymbol{p}$ of the pension is to be included as in (8a), $q$ has to be substituted by $q / p$, $p \neq q$. in formulae (1) to (1e). With user defined functions $\operatorname{GAFk}(r ; n ; q / p)$ computation of the present value (8a) can be done very efficiently in a unique EXCEL-cell. For the general closed formula of GAF see Wilde (2018).

In Figure 4 the biometric pension payment function for our numerical example is shown for 35year old male and female employees. Assuming the biometry of the pool of the fund members is conform with the national mortality table, the fund can count on probable pension payments as shown in Figure 4. Thus, additional to PV-calculation according to (8a), individual cashflow projections for each member of the fund, active worker and retiree, can be efficiently prepared according to the actual age structure of the members.

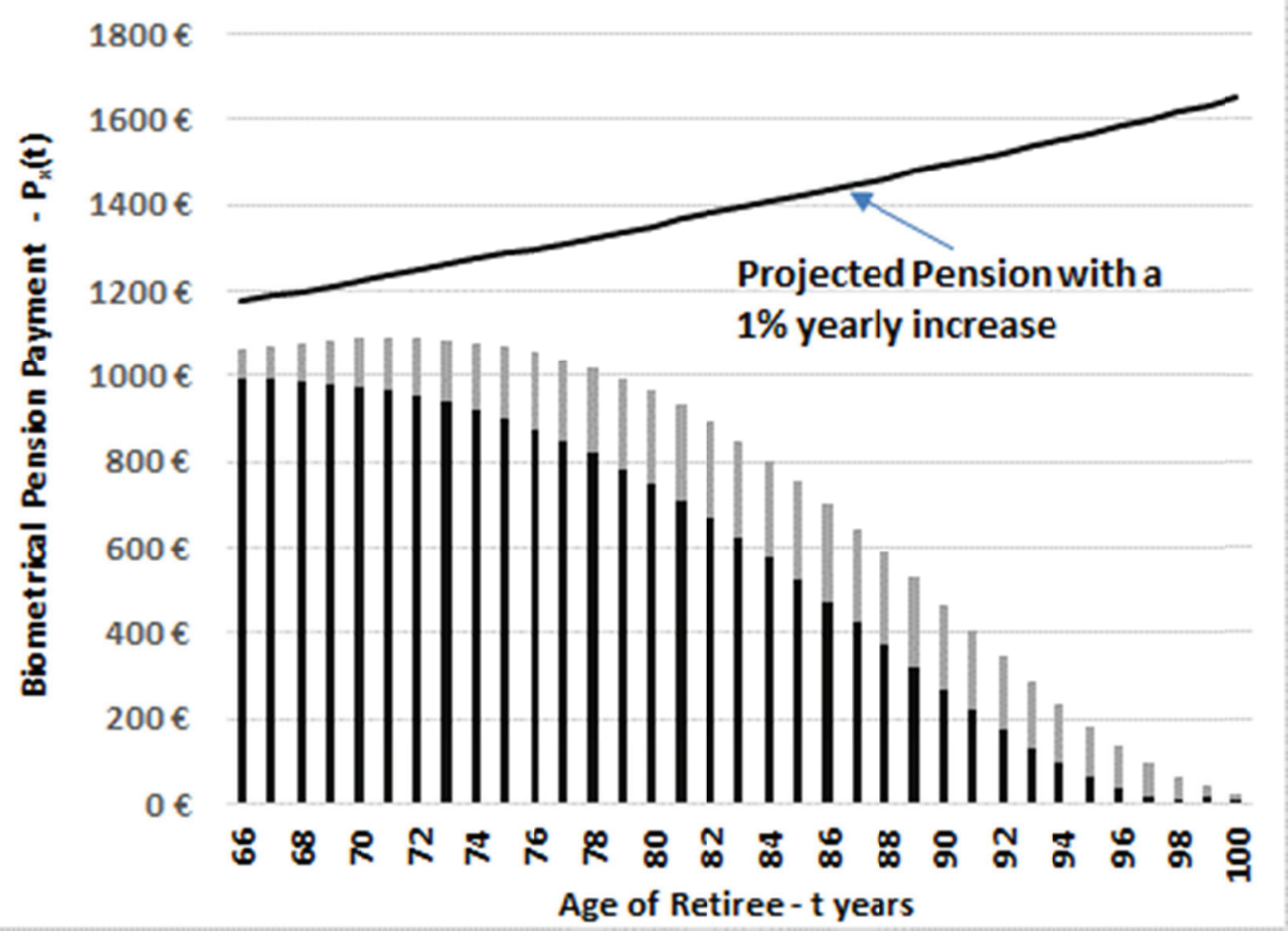

Figure 4. Projected pension with a yearly pension increase of $p \%=1 \%$ in comparison with the projected biometric pension payments to men (black bars) and women (additional grey bars) for $x=35$ year old active workers 
Apparently, for rather young active workers as in our example ( $\mathrm{x}=35$ years) the projected biometric pension payments in their first retirement year (66) are notably below the projected pension of $1164 €$. This is because of the mortality during the long-time period between the actual age of 35 and the retirement age of 65 years, which is higher especially for men. With increasing age of the active worker, the projected biometric pension approaches the projected pension.

The figure shows clearly the strong decline of the biometric pension payments the fund can expect in average for retirees of a certain age $t$. Whilst the biometric payments for male retirees always decline from the beginning of the retirement, we observe an increase for female retirees until an age of 73 years. The reason is that until this age the reduction of their survivorship probabilities is below the yearly pension increase of $p \%=1 \%$.

In order to make the content of (8) and (8a) intuitively accessible, we continue our numerical example to evaluate the specific biometric payment function regarding mortality and its present value using GAF.

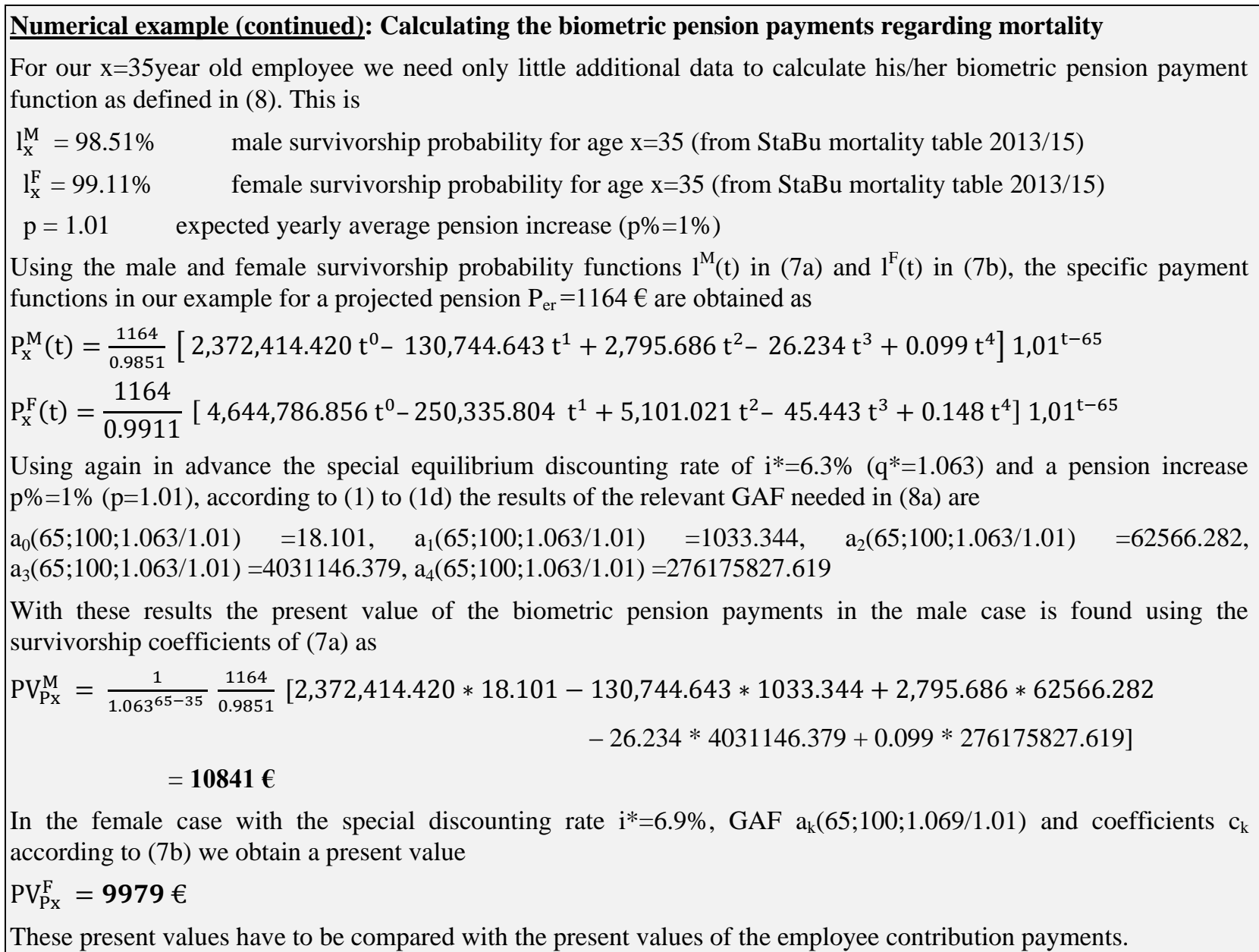

\subsection{The Pension Rate of Return (PRR)}

The Internal Rate of Return (IRR) is generally used to evaluate the attractiveness of an investment (Lyuu, 2002). IRR is best suited for analysing capital investments entailing only positive cash flows of the same duration after investment (Bosri, 2016). This is the case with pension payments being always positive and referring to the same maximum age of the mortality table. Finally, the Pension Rate of Return (PRR) $i *$ resp. the according factor $q^{*}=1+i^{*}$ is determined as that special discounting rate resp. factor, for which the present value of the contribution payments of the employee subject to (2a) equalizes the present value of the pension payments to the employee regarding mortality subject to $(8 \mathrm{a})$ :

$$
i^{*} \text { resp. } q^{*} \text { for: } \quad P V_{C A}\left(q^{*}\right)=P V_{P X}\left(q^{*}\right)
$$


The internal rate of equilibrium of the present values cannot be derived analytically. It can only be found by an iterative procedure using a convergence criterion to come stepwise to a stable solution. Such an iterative procedure can easily be implemented in the same spreadsheet in which the foregoing calculations are done.

\section{Numerical example (continued): Calculating the Pension Rate of Return (PRR)}

We refer to the calculations of the present value of the employee contribution payments and the present value of the pension payments regarding mortality. In these calculations in chapter 2.1 and 2.3 we already in advance used the $\mathrm{PRR}$ as a discounting rate.

In the male case of our example the equilibrium according to (9) is $\mathrm{PV}_{\mathrm{CA}}=\mathrm{PV}_{\mathrm{Px}}=\mathbf{1 0 , 8 4 1} €$ for a $\mathbf{P R R} \mathrm{i}^{*}=\mathbf{6 . 3 \%}$ or $\mathrm{q}^{*}=1.063$. In the female case of our example we find a higher PRR $\mathbf{i}^{*}=\mathbf{6 . 9 \%}$ or $\mathrm{q}^{*}=1.069$ to come to an equilibrium at $\mathrm{PV}_{\mathrm{CA}}=\mathrm{PV}_{\mathrm{Px}}=\mathbf{9 , 9 7 9} €$. Only five steps of a converging iteration procedure are necessary, to come to sufficiently stable PRR-scores.

Compared with the low fund interest rate (3\% p.a.), the PRR's of $6.3 \%$ resp. $6.9 \%$ p.a. are much higher. The additional positive return effect of employer's contribution makes our corporate pension scheme a very attractive investment relative to the contributions invested by the employee!

\subsection{Calculating Present Value of a l€-Lifetime Annuity with GAF}

Calculation of the typical present value of a $1 €$-lifetime annuity $a_{r}$ at retirement age $\boldsymbol{r}$ is only necessary, if no information of the projected pension is provided by the fund.

With GAF, using the coefficients of the survivorship functions (7a resp. 7b), a direct gender specific calculation of $a_{r}^{M}$ for male and of $a_{r}^{F}$ for female members is possible (Wilde, 2016)

$$
\begin{gathered}
a_{r}^{M}=\frac{1}{l_{r}^{M}} \sum_{k=0}^{4} c_{k}^{M} \boldsymbol{a}_{\boldsymbol{k}}\left(\boldsymbol{r} ; \boldsymbol{n} ; \frac{\boldsymbol{q}_{\boldsymbol{F}}}{\boldsymbol{p}}\right) \\
a_{r}^{F}=\frac{1}{l_{r}^{F}} \sum_{k=0}^{4} c_{k}^{F} \boldsymbol{a}_{\boldsymbol{k}}\left(\boldsymbol{r} ; \boldsymbol{n} ; \frac{\boldsymbol{q}_{\boldsymbol{F}}}{\boldsymbol{p}}\right) \quad ; \mathrm{p} \neq \mathrm{qF}
\end{gathered}
$$

using the fund interest rate $i_{F}$ resp. $q_{F}$ and pension indexation $p$ for discounting. Weighting (10) and (10a) with their male and female shares in the member pool a present value of a unisex $1 €$-lifetime annuity is derived

$$
a_{r}^{U}={ }_{M} f a_{k}^{M}+{ }_{F} f a_{r}^{F}
$$

\footnotetext{
Numerical example (continued): Calculating the present value of a unisex $1 €$-lifetime annuity

With the fund interest rate of $\mathrm{i}=3.0 \%(\mathrm{q}=1.03)$, a pension increase $\mathrm{p} \%=1 \%(\mathrm{p}=1.01)$ and a retirement age $\mathrm{r}=65$, according to (1) to (1d) we calculate the relevant GAF needed in (10) and (10a) as

$\mathrm{a}_{0}(65 ; 100 ; 1.03 / 1.01)=25.076, \quad \mathrm{a}_{1}(65 ; 100 ; 1.03 / 1.01)=2031.579, \quad \mathrm{a}_{2}(65 ; 100 ; 1.03 / 1.01)=167087.924$, $\mathrm{a}_{3}(65 ; 100 ; 1.03 / 1.01)=13947485.721, \quad \mathrm{a}_{4}(65 ; 100 ; 1.03 / 1.01)=1181068307.244$

and we then immediately find the present value of a $1 €$-lifetime annuity in the male case as

$a_{r}^{M}=\frac{1}{0.9851}[2,372,414.420 * 25.076-130,744.643 * 2031.579+2,795.686 * 167087.924$

$-26.234 * 13947485.721+0.099 * 1181068307.244]$

$=12.14 €$

and in the female case as

$a_{r}^{F}=\frac{1}{0.9911}[4,644,786.856 * 25.076-250,335.804 * 2031.579+5,101.021 * 167087.924$

$-45.443 * 13947485.721+0.148 * 1181068307.244]$

$=15.01 €$

With a $60 \%$ weight of the male members - therefore $40 \%$ weight of the female members - a unisex present value of a $1 €$-lifetime annuity is obtained

$a_{r}^{U}=0.6 * 12.14+0.4 * 15.01=\mathbf{1 3 . 2 9} €$

This result has been inserted in (4), (5) and (5a) to obtain the projected (unisex) pension $\mathrm{P}_{\mathrm{er}}$.
} 


\section{Determinants of the Pension Rate of Return (PRR)}

The new method makes it possible to analyse efficiently the effects of many determinants on the PRR on an individual base, especially the effects of different interest fund rate levels, different employer's contribution fractions, governmental savings promotions and different administration costs. But even biometry of the pool of the insured members may have an impact on PRR. However, the absolute amount of salary and as well the absolute level of the contribution rate do not affect the PRR. As the PRR-calculations are based on total mortality tables and therefor do not refer to specific death years, they are generally valid.

\subsection{Return Effect of Compound Interest on PRR}

Corporate pension schemes as capital funded systems rely on adequate interest returns for taking financial risks for their investments. Figure 5 shows the huge effect of higher fund interest rates $i_{F}$ due to compound interest on the monthly pension $P_{e r}$ for our case configuration with an employer contribution fraction of two third: it ranges from a monthly pension of $7587 €$ at a fund interest rate of $9 \%$ p.a. down to a monthly pension of $484 €$ at a fund interest rate of $0 \%$ ! The assumption of our case configuration is that the fund interest rate $i_{F}$ during the whole working lifetime between entry age $e$ and retirement age $r$ is the same.

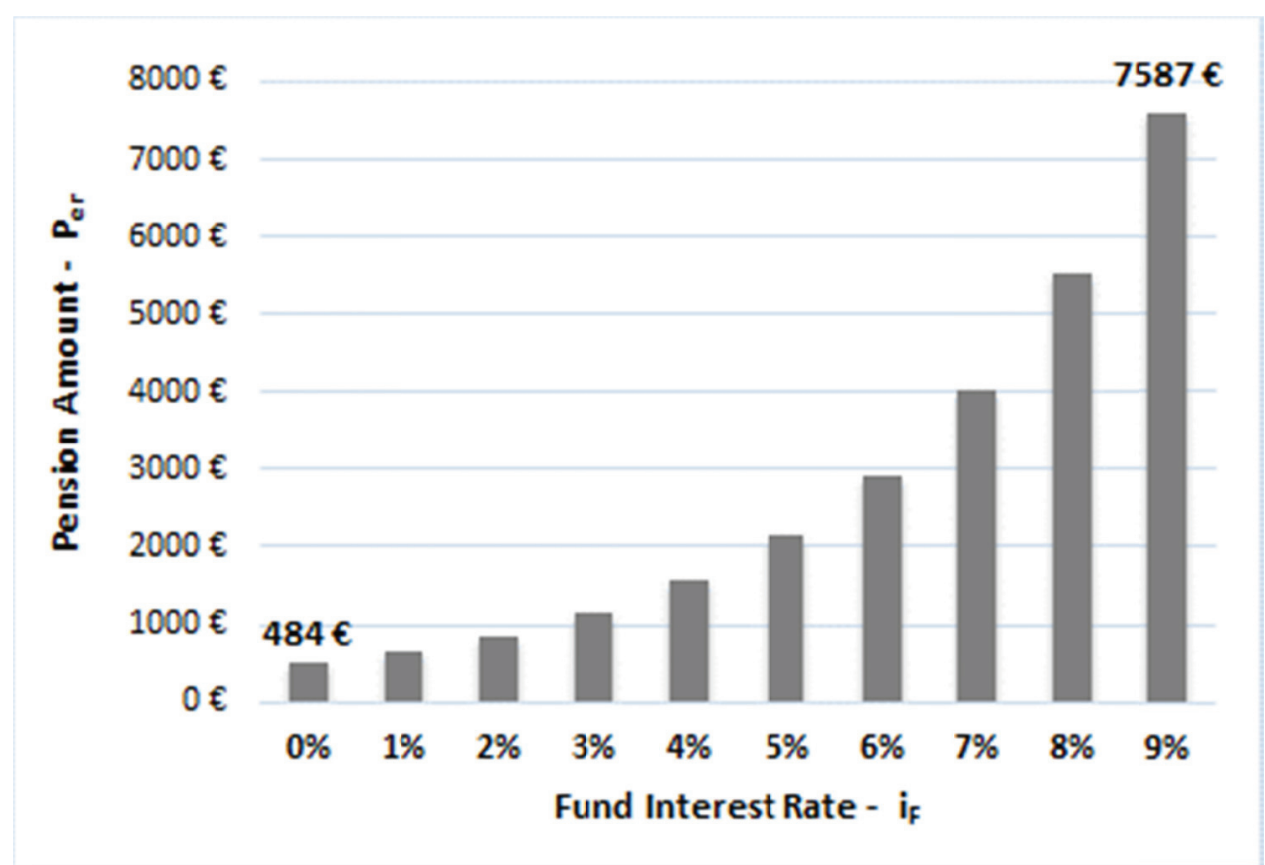

Figure 5. Effect of increasing fund interest rates $i_{F}$ on the projected pension $P_{e r}$ (monthly payment)

Figure 6 describes the same context, but we now look at the relative return effect, denoted by the PRR. Looking at the worst case of no interest at all $(0 \%)$ we still see a PRR of 3.4\% which is owed the employer contributions fraction of two third in our example. This is a very important message: even in a world without interest, corporate pension schemes still have a positive PRR depending on the corporate fraction of contributions! 


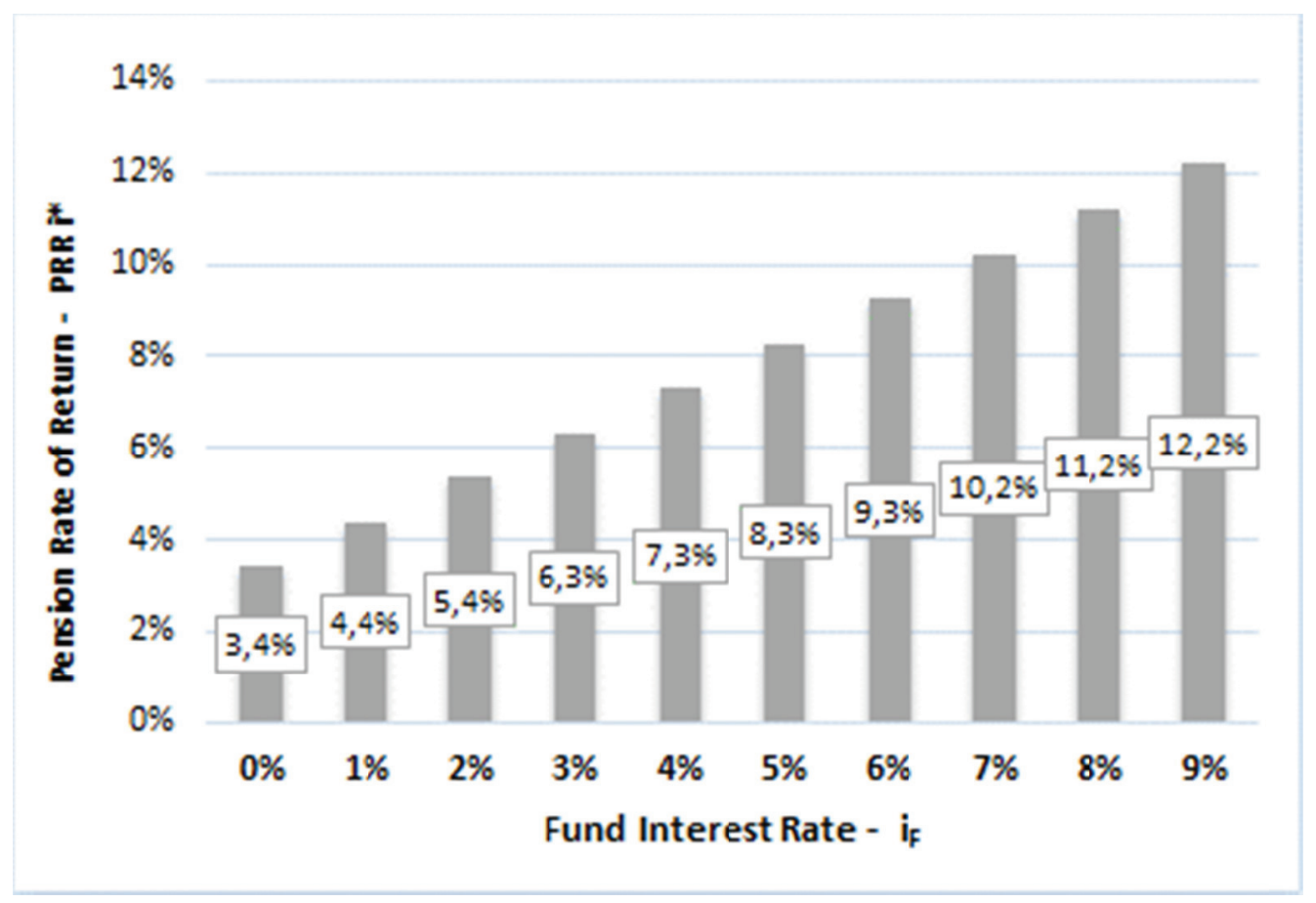

Figure 6. Effect of increasing fund interest rates $\mathrm{i}_{\mathrm{F}}$ on PRR $\mathrm{i}^{*}$

\subsection{Return Effect of Employer's Contributions on PRR}

For our numerical example with contribution rates of $2 \%$ for the employee and $4 \%$ for the employer, meaning an employer fraction of $66.7 \%$ of the total contribution rate of $6 \%$, we obtained a monthly pension of $1164 €$ and a PRR of $6.3 \%$ in the male case. Assuming now total contribution of $6 \%$ being solely paid by the employee, meaning an employer contribution fraction of $0 \%$, we still obtain the same pension level of $1164 €$, but a PRR of only $\mathbf{2 . 7 \%}$ ! The big difference shows again, that besides the level of the fund rate obviously the fraction of the employer contributions plays an important role for the performance of a corporate pension scheme. The impact of an increasing employer contribution fraction on PRR $i^{*}$ is systematically shown in Figure 7 . In the female case the rates are even $0.6 \%$ higher. 


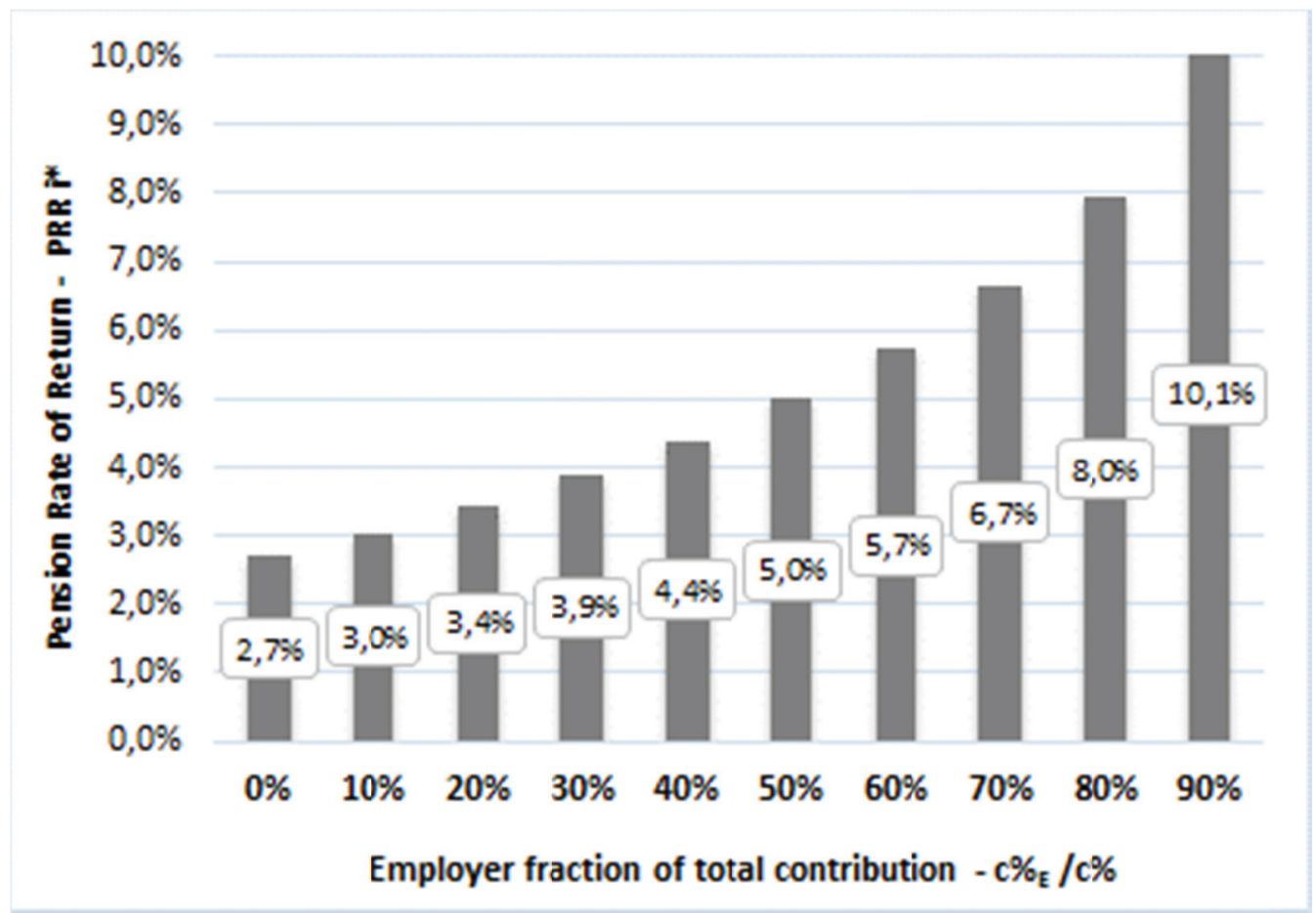

Figure 7. Effect of an increasing employer contribution fraction on PRR $i *$ (male members)

Without any employer contribution ( $0 \%$ ) the PRR is only $2.7 \%$, which is even below the fund interest rate of $3 \%$. This is caused by the disadvantageous unisex-calculation and lower survivorship probabilities (see Figure 4) for male members. Accordingly, in the zero-case the PRR for female members of $3.4 \%$ is higher than the fund interest rate. In the other extremal case, when the employer takes all the contributions to the fund, the PRR becomes infinite. The constellation of our example with an employer contribution fraction of $66.7 \%(=4 \% / 6 \%)$ leading to a PRR of $6.3 \%$ is located between the $60 \%$ and $70 \%$ bars in Figure 7.

Can higher employer contributions compensate lower fund interest returns?

All over the world, corporate pension schemes are hit hard by the ultra-easy money policy of the leading central banks. When interest as an important source of return gets dried out, the question is whether the breakdown of this source of return could be partly or totally compensated by other sources. In a corporate pension scheme, of course higher employer contributions are in focus as corporates just like states are profiteers of the ultra-easy money policy because of lower financing costs. Therefore, the idea seems justified, that corporates should share their financing profits on the borrowing side to some extent with their employees being the losers on the saving side.

A quantitative answer to this question in form of a full compensation of a fund interest reduction by higher employer contributions in order to preserve a certain pension level (here $1164 €$ ) is given in Figure 8. Off course also a smaller compensation could be helpful. 




Figure 8. Full compensation of melting fund interest rates by growing employer contribution fractions

If the fund interest rate is $6.6 \%$ p.a. there is no need of any employer contribution to hold the monthly pension level of $1164 €$. For lower levels of fund interest rates Figure 8 shows the growing employer contribution fraction necessary for full compensation. In our example for a fund interest rate level of $3 \%$ an employer fraction of $66.7 \%=$ $4 \% /(2 \%+4 \%)$ was necessary for a monthly pension level of $1164 €$. A lower interest rate level of $1 \%$ needs a compensating employer fraction of $75,2 \%$. If the fund interest rate turns down to zero, an employer contribution fraction of about $86 \%$ is needed to keep the pension level equal. Figure 8 also includes the new reality of negative interest rates. Even a negative fund interest rate of $-1.1 \%$ could be compensated by a $90 \%$ employer contribution fraction.

\subsection{Return Effect of Governmental Savings Promotion on PRR}

In order to promote savings for old age some countries grant government subsidies not only to private but also to corporate pension schemes. The forms of governmental-sponsored corporate pension schemes differ from country to country. As an example, we will model the German savings promotion system called "Riester Rente" (Riester Pension), named after the former German Minister of Labour and Social Affairs, (Schlemann, 2019). Besides a yearly basic bonus throughout

the whole active working lifetime an additional time-limited yearly child bonus for each child is granted by government.

With these government subsidies covering funds (3) and (3a) will be increased by an additional component $\boldsymbol{C F}_{\boldsymbol{G}}$ including compound interest

$$
C F_{G}=B B \quad q_{F}^{r-e} a_{0}\left(e ; r ; q_{F}\right)+j C B\left[q_{F}^{b-e} a_{0}\left(e ; b ; q_{F}\right)-q_{F}^{a-e} a_{0}\left(e ; a ; q_{F}\right)\right] \frac{q_{F}^{r-b}}{q_{F}^{a-e}}
$$

where

$B B=$ basic bonus for the Active Worker (for the whole working life)

$C B=$ child bonus for each child of the Active Worker (limited to max. 25 years)

$a=$ starting age of the active worker for child bonus $(a>e)$

$b=$ finishing age of the active worker for child bonus $(b<r)$ 
$j=$ number of children $(j=0,1,2, \ldots)$

The total projected pension then will be

$$
P_{e r}=\left(C F_{e X}+C F_{x r}+C_{F G}\right) / a_{r}^{U}=P_{e X}+P_{x r}+P_{G}
$$

with an additional governmental pension component $P_{G}$.

\section{Numerical example (continued): Calculating the return effect of governmental savings promotion \\ Using the conditions of the German "Riester Rente" with a basic bonus $\mathrm{BB}=175 €$ and a child bonus $\mathrm{CB}=300 €$ \\ for $j=2$ children with a promotion period of 25 years from age $a=30$ to age $b=55$ and including the compound interest effect as well initiated by the bonus payments, additional governmental covering funds $\mathrm{CF}_{\mathrm{G}}$ and thus governmental pension payments $\mathrm{P}_{\mathrm{G}}$ are generated in the amount of

$$
\mathrm{P}_{\mathrm{G}} \quad=42594 / 13.29 / 12=\mathbf{2 6 7} € \text { per month }
$$$$
\begin{array}{rl}
\mathrm{CF}_{\mathrm{G}}=175 & * 1.03^{65-25} \mathrm{a}_{0}(25 ; 65 ; 1.03)+2 * 300\left[\begin{array}{r}
1.03^{55-25} \mathrm{a}_{0}(25 ; 55 ; 1.03) \\
-1.03^{30-25} \mathrm{a}_{0}(25 ; 30 ; 1.03)
\end{array}\right] \frac{1.03^{65-55}}{1.03^{30-25}} \\
= & 42594 €
\end{array}
$$

Compared with pension solely financed by contributions of the active worker $\left(\mathrm{c} \% \mathrm{~A}_{\mathrm{A}}=2 \%\right)$ the table below shows the effects of employer $\left(\mathrm{c} \%_{\mathrm{E}}=4 \%\right)$ and government (bonus as above) sponsoring on the pension amount and the rate of return:

\begin{tabular}{lcc} 
Contributions from & Pension amount & \multicolumn{2}{c}{ PRR } \\
only Employee & $388 €$ & $2.7 \%$ \\
Employee \& Employer & $1164 €$ & $6.3 \%$ \\
Employee \& Employer \& Government & $1431 €$ & $7.0 \%$
\end{tabular}

The table clarifies the importance of employer and in addition of governmental sponsoring for a corporate pension scheme.

The German conditions for governmental savings promotion used in this example can easily be adjusted to the conditions of other countries.

Can additional government subsidies help to compensate interest melting?

As mentioned before, pension funds do not realize adequate interest returns for taking financial risks anymore. In the end saving returns as well as future pension claims will be massively reduced in favor to a costless or even profitable (in the case of negative interest) financing of state households. In this respect at least a partial compensation of saving or pension losses by higher governmental promotions is more than justified.

With the new method we can immediately calculate additional necessary governmental promotions to compensate an interest reduction, for example from $\boldsymbol{i}_{F}=\mathbf{3 \%}$ to $\boldsymbol{i}_{F}=\mathbf{2 \%}$ keeping all other data at the level of the foregoing example, especially a monthly pension $P_{e r}=1431 €$ with the German subsidies described before. The pie chart on the left of Figure 9 shows the percentages of the different sources of this pension with an interest level of $i_{F}=3 \%$. The pie chart on the right shows the situation for a lower interest level of $2 \%$ and compensation by higher governmental and employer sponsoring. Without compensation the monthly pension would sink to $1059 €$. The difference to $1431 €$ is compensated by a doubling of the basic and the child governmental bonus (now 350 resp. $600 €$ ) and a moderate raise of the employer contribution rate from $4 \%$ to 5.25\%. Comparison of the pie charts in Figure 9 shows the shift between the sources 


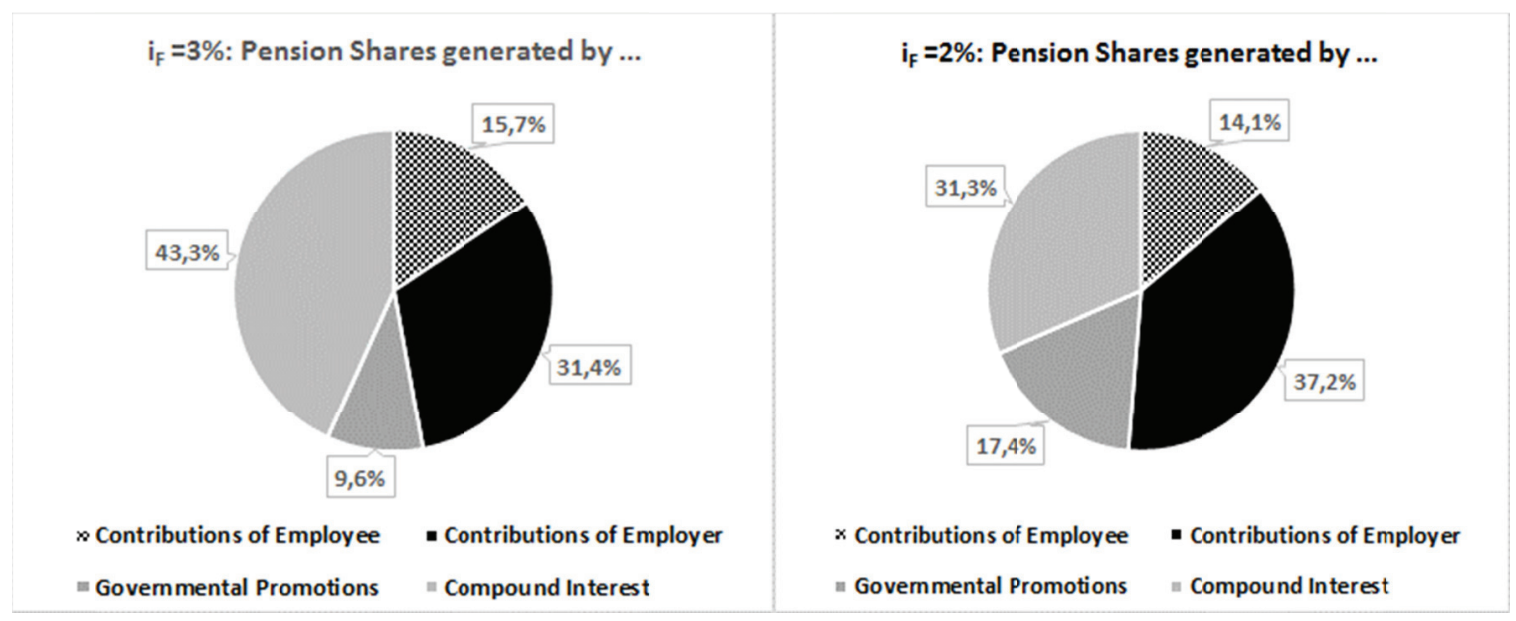

Figure 9. Compensation of melting interest by higher governmental and employer sponsoring

Because of interest melting from $3 \%$ to $2 \%$ the pension share caused by compound interest shrinks from $43.3 \%$ to $31.3 \%$. The reduction can be absorbed by bigger pension shares of $17.4 \%$ due to stronger governmental savings promotions by doubling the basic and the child bonus and of $37.2 \%$ due to raising the employer contribution rate from $4 \%$ to $5.25 \%$ of the monthly salary. Without the higher governmental pension share the employer contribution rate would have to be raised to $6.6 \%$ to keep the pension on the same level.

\subsection{Return Effects of Administration Costs on PRR}

With the new method the positive absolute and relative return effect, if administration costs of the fund are absorbed by the employer, can be shown easily. Assuming administration costs in amount of $10 \%(20 \%)$ of the total contributions, these contribution amounts do not take part in building up the covering funds until retirement. In our example this leads to a pension reduction of $116 €(233 €)$ and a PRR-reduction of $0.3 \%(0.7 \%)$. Vice versa these are the positive return effects if the employer does not burden the fund with these costs.

\subsection{Return Effects of Mortality Deviations in the Fund's Member Pool on PRR}

Often the insured of a corporation show mortality deviations in respect to the general mortality of the population measured by the national mortality tables. Therefore, adjustment might be necessary. For example, a systematic lower mortality of the insured can be incorporated by a calculative rejuvenation of $\mathbf{d}$ years taking the higher survivorship probability of a $x$ - $d$ year old person instead of the probability of the real age of $x$ years. Using GAF we only have to substract $d$ in the ,biometric“ terms $l_{x-d}, a_{k}(r-d ; n ; q / p)$ in (8a) and $a_{k}\left(r-d ; n ; q_{F} / p\right)$ in (10). The specific score of the necessary calculative rejuvenation $\mathbf{d}^{*}$ for an insured pool can be calibrated in such a manner that the calculated total pension provisions using $\mathrm{d}^{*}$ equals the total actuarial pension provisions.

Assuming a calculative rejuvenation of $\mathrm{d}^{*}=5$ years for the members of the insured pool of our example causes a big reduction in absolute return (projected pension) from $1164 €$ to $953 €$ but only a small reduction in relative return (PRR) from $6.3 \%$ to $6.2 \%$. The reason is that because of the longevity, payment probabilities of the lower pension are much higher. But if the calculative rejuvenation does not prove to be true, this has a very negative effect on the PRR. It turns down to $5.7 \%$.

\subsection{Return Effects of a Later Entry in the Pension Fund on the PRR}

In our example we considered the case of an entry at age 25 . But what about later entry ages? The answer is given in Table 1 under equal conditions otherwise. 
Table 1 . PRR of later entry ages $e$

\begin{tabular}{rrr}
$\begin{array}{l}\text { Entry } \\
\text { at age e }\end{array}$ & $\begin{array}{c}\text { PRR } \\
\text { male }\end{array}$ & $\begin{array}{c}\text { PRR } \\
\text { female }\end{array}$ \\
\hline $\mathbf{2 5}$ & $6,3 \%$ & $6,9 \%$ \\
$\mathbf{3 5}$ & $7,1 \%$ & $7,8 \%$ \\
$\mathbf{4 5}$ & $8,4 \%$ & $9,3 \%$ \\
$\mathbf{5 5}$ & $11,1 \%$ & $12,3 \%$ \\
\hline
\end{tabular}

Table 1 proves that - perhaps contrary to expectation - the PRR with a later entry age strongly increases. This has two reasons: approaching retirement, on the one hand survival probabilities increase and on the other hand the discounting effect diminishes. The strong increase of PRR, especially for women, makes clear that it makes sense to enter a pension fund at a later age and that it makes no sense to leave a pension fund at a later age.

\section{Conclusions}

The new method of GAF makes it possible not only name but also quantify the performance factors of a corporate pension scheme. The Pension Rate of Return (PRR) regarding mortality makes pension schemes comparable with other assets for retirement which is crucial for an old age financial planning.

Because of the large number of insured persons an efficient closed formula-based computation of a financial key number like PRR is crucial: GAF can be computed recursively starting from the well-known classic Annuity Factor. Having defined the payment functions, here the employee's payment function in chapter 2.1 and the biometric pension payment function in chapter 2.3, the according present value is directly derived in only one cell of a spread sheet program by simply substituting the time terms of payment functions by the according GAF. Because the results refer to the total mortality table they hold in general and are not restricted to specific death years.

What are the determinants of the PRR? In chapter 3.1. and 3.2 we found the fund interest rate and the employer's contribution fraction of the total contribution to be the most important determinants. Analysing the compensation of a melting fund interest level by a higher employer contribution fraction, keeping the pension on the same level, we found out that an interest reduction from 3 to $2 \%$ had to be compensated by rising the employer contribution rate from $4 \%$ to $6 \%$ (fraction from $66,7 \%$ to $75,2 \%$ ) in our example. The reason why it is so hard to compensate interest reductions is the compounding effect over the long-time period from the entry into the pension fund until retirement.

Furthermore, we analysed in chapter 3.3 whether higher governmental savings promotion in addition to higher employer's contribution could prevent a pension cutback due to melting interest rates (from $3 \%$ to $2 \%$ ). Such a combination may, for example, consist of a moderate raise of the employer contribution rate (from $4 \%$ to $5.25 \%$ ) and of a distinct lift of the governmental bonus (from $675 €$ to $1350 €$ per year). We believe this is socially justified. Due to the ultra-light money policy of the Central Banks both, the corporate and the public sector, benefit greatly at the expense of savers and future pension receivers. Therefore at least a partial compensation should be worth considering.

In the past, information in annual financial reports of a fund mostly was addressed to professional readers like bookkeepers, investors or governmental institutions. The performance of a corporate pension scheme has been mostly shown by the realized asset rate of return. As we have seen from the view of the insured the PRR is more relevant because it shows the profitability of the employee contributions. The individual PRR should be reported in the yearly official information note of the fund to the insured. Together with the projected absolute pension amount, the individual PRR is the appropriate pension information for the insured. For a general PRR information for instance, the following statements in an annual report may serve (Pension Fund of Water Associations, 2018): even in the worst-case constellation (new employment \& employer with a low contribution share \& no governmental promotion) a PRR of $2.3 \%$ for male and of $3.0 \%$ for female members is realized. All long-time insured members, who profit from earlier higher fund interest rates and/or have employers with higher contribution shares, will enjoy a PRR of at least $4 \%$ in our pension fund. No other asset with a comparable risk can offer such a high performance.

Further development of the model is possible differentiating model parameters concerning salary, contribution and fund return over the often-long-time period until retirement. This could be achieved by a three-stage model also seeding three different fund interest rates for the past, near future and residual time until retirement. As could be 
shown, GAF make it also possible, to include pension for dependants. Another interesting field of future research is to analyse the impact of matching-procedures between employer and employee contributions.

\section{References}

Bosri, R. (2016). Evaluation of Managerial Techniques: NPV and IRR. UITS Journal, 5(1), 48-57

Collinson, D. (2001). Actuarial Methods and Assumptions used in the Valuation of Retirement Benefits in the EU and other European countries. Oxford, England: EUROPEAN ACTUARIAL CONSULTATIVE GROUP.

EU-Directive 2016/2341 (2016). On the Activities and Supervision of Institutions for Occupational Retirement Provision (IORPs), Official Journal of the European Union.

Guo, Z.-Y. (2017). Health Insurance and the Demand for Medical Care: a Case Study from China. Asian Journal of Economics and Empirical Research, 4(1), 8-13. https://doi.org/10.20448//journal.501.2017.41.8.13

Halley, E. (1761). Of Compound Interest. Henry Sherwin, Sherwin's Mathematical Tables, published posthumously after Halley's death in 1742. London, England: W. and J. Mount, T. Page and Son

Lyuu, Y. (2002). Financial Engineering and Computation: Principles, Mathematics, Algorithms. Cambridge, England: University Press

Pension Fund of Water Associations (2018). Annual Report 2018, Essen.

Phillips, G. \& Taylor, P. J. (1996). Theory and Applications of Numerical Analysis (2 ${ }^{\text {nd }}$ ed.). London, England: Elsevier Academic Press

Rubinstein, M. (2003). Great Moments in Financial Economics: I. Present Value. Journal of Investment Management, 1.Q. 2003, 1-17

Schlemann, B. (2019). Riester Pension: an English Explanation of the Riester Pension Scheme, https://schlemann.com/altersvorsorge/riester-rente/riester-pension-english/, 13.08.2019

Statistisches Bundesamt (2014). Aktuelle Sterbetafel für Deutschland 2013/2015. Retrieved from https://www.destatis.de/DE/Publikationen/Thematisch/Bevoelkerung/Bevoelkerungsbewegung/Sterbetafeln AllgemeinErlaeuterung5126205129004.pdf?_blob=publicationFile (Translation of title: Actual Mortality Table for Germany 2013/2015)

Wilde, J. (2005). Ein neues allgemeines Verfahren zur direkten Barwertermittlung für diskrete zeitabhängige Zahlungsprozesse. Vortrag vor dem Ökonomischen Forschungsseminar an der Westfälischen Wilhelm Universität Münster am 21.12.2005, 1-21 (Translation of title: A New General Approach of Computing Present Values for Discrete Time Dependent Payment Processes)

Wilde, J. (2016). Der Allgemeine Rentenbarwertfaktor als effizientes Controlling-Instrument für Pensionsverpflichtungen - von besonderer Bedeutung in Zeiten der Zinsschmelze. CONTROLLING - Zeitschrift für erfolgsorientierte Unternehmenssteuerung, 28(9), 676-685. https://doi.org/10.15358/0935-0381-2016-11-676 (Translation of title:The General Annuity Factor as an Efficient Controlling Instrument for Pension Obligations - of Especial Importance in Times of an Interest Melting)

Wilde, J. (2018). Generalization of the Annuity Factor. Accounting and Finance Research, 7(2), 83-95. https://doi.org/10.5430/afr.v7n2p83

Wilde, J. (2019). VAG-Novellierung macht Runderneuerung der Versicherteninformation notwendig. Warum nicht aus der Not eine Tugend machen? Macht die bAV-Renditen transparent! BetrAV Betriebliche Altersversorgung, 74(2), S. 355-361 (Translation of title: Amendment of the European Insurance Regulation Law Makes a Renewal of Information Policy Necessary. Why not Make a Virtue out of Necessity? Make the Pension Rates of Return transparent!) 